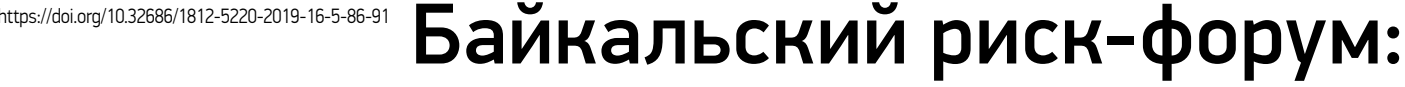 системный подход, прикладные решения
}

\section{Baikal risk forum: System approach, Application solutions}

\begin{abstract}
В конце сентября в Иркутске прошел третий Международный байкальский форум по управлению рисками. Уникальность его заключается в том, что площадка для обмена лучшими практиками и инструментами управления рисками организована самим бизнесом и для бизнеса. А значит, характер имеет самый что ни на есть практический. Едут сюда и за свежими идеями, и за прикладными решениями.
\end{abstract}

«Именно концентрация компетенций, знаний и опыта делает форум максимально полезным для бизнеса», - полагает Марина Седых, генеральный

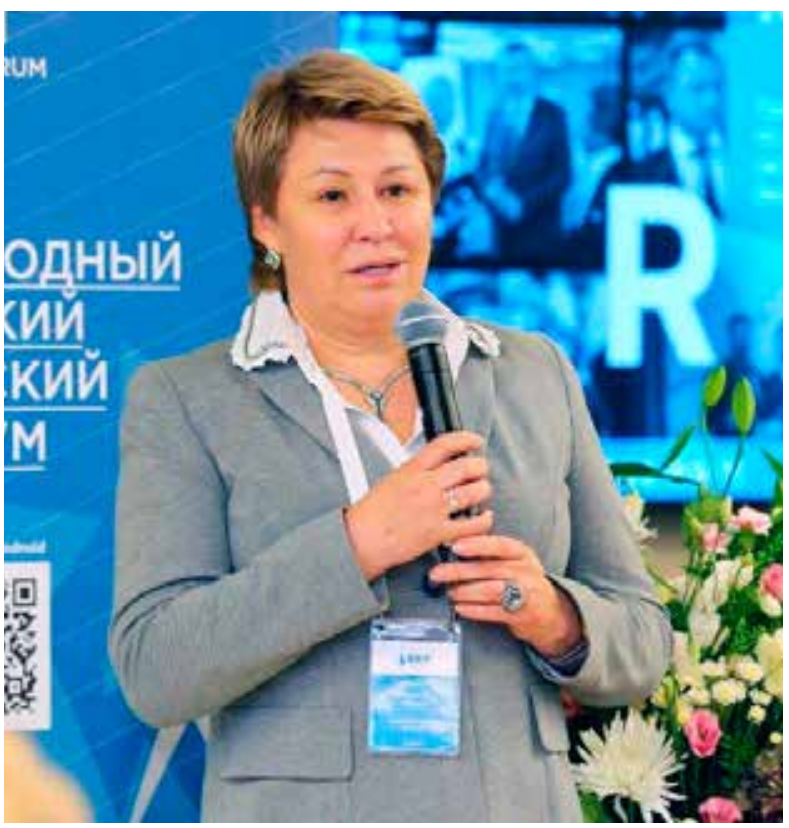

Марина Седых, генеральный директор Иркутской нефтяной компании директор Иркутской нефтяной компании, выступившей организатором форума.

Исторически построение риск-менеджмента началось с крупных компаний. Вот и сейчас на сибирской площадке собрались представители глобальных лидеров риск-менеджмента - таких, как Microsoft, Газпром, Норникель, Атомэнергомаш, АЛРОСА, Уралкалий, Мегафон, MTC, KLR, ERG, Интер РАО, Schneider Electric, ДОМ.РФ, Национальный расчетный депозитарий, КРОК, АльфаСтрахование, Ингосстрах и многих других, а также эксперты из Deloitte, PwC, KPMG, ISAR, Риск-академии. Было сделано более 60 докладов. Всего же в форуме приняли участие более трехсот человек. Наш журнал «Проблемы анализа риска» выступил информационным партнером мероприятия.

На повестке дня стоял ключевой вопрос - непрерывность бизнеса и возможность управления ею. Темы для обсуждений раскрывали все аспекты проблемы - непрерывность производственных процессов, непрерывность в области ИТ и киберриски, непрерывность снабжения и электроснабжения, непрерывность в области финансов, правовые риски, риски в случае чрезвычайных ситуаций, оценка воздействия на бизнес. Участники форума 


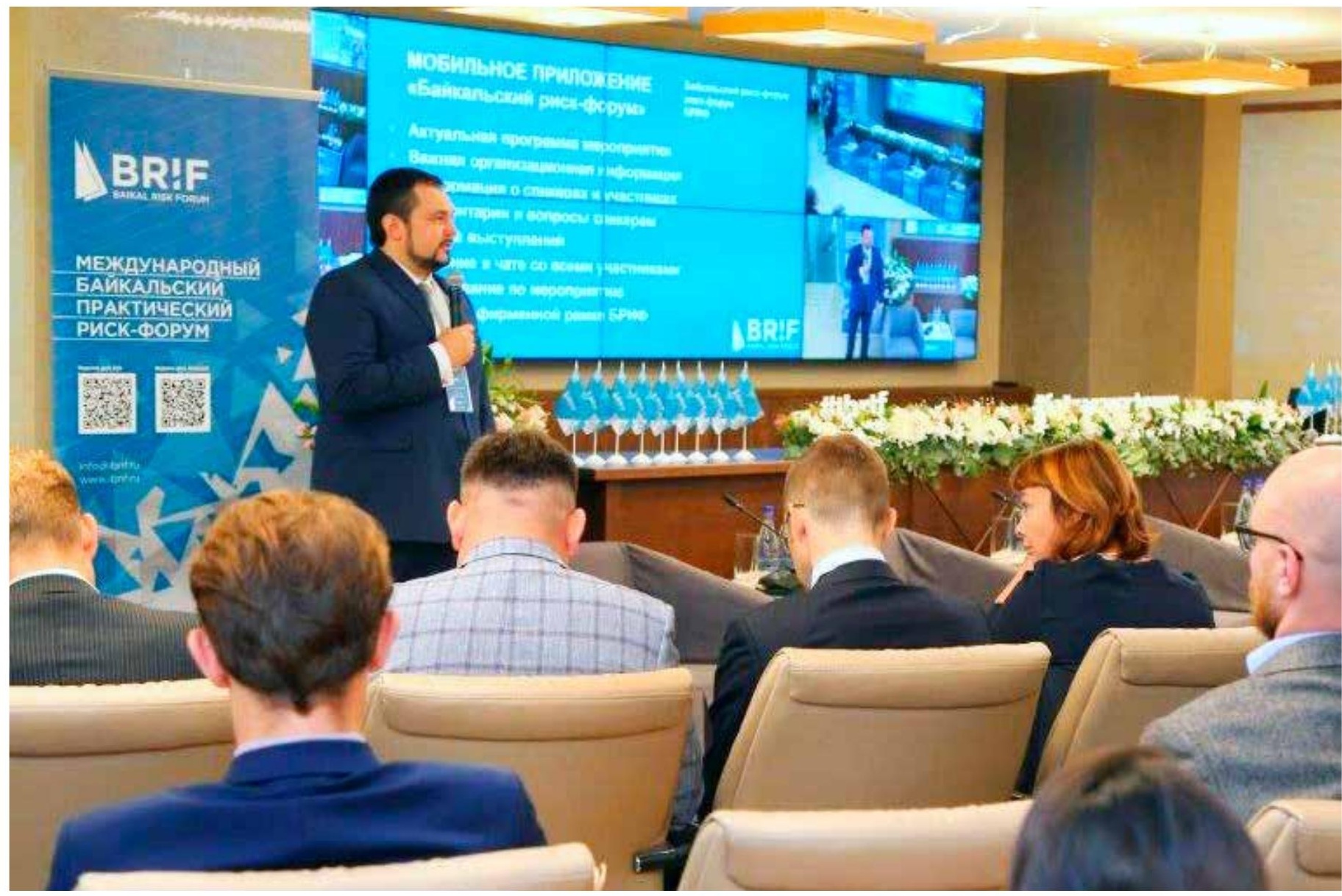

рассказывали о том, как разрабатывают планы непрерывности в крупнейших российских компаниях, о чем важно помнить при внедрении этих планов, делились своими инсайтами и лайфхаками.

Надо сказать, практические кейсы по управлению непрерывностью бизнеса вызывали неподдельный интерес аудитории и живой отклик. И неудивительно, если учесть, что постоянно меняющиеся неопределенности, повышенная волатильность, а также растущие масштабы и количество кризисов продолжают влиять на экономический рост компаний.

Отметил это и специальный гость из Японии Масахико Сугияма (Masahiko Sugiyama), руководитель практики по антикризисному управлению, японский партнер Deloitte. Он поделился с участниками результатами последнего исследования Deloitte по непрерывности бизнеса и кри- зис-менеджменту в Стране восходящего солнца. Согласно этому исследованию, почти 60\% компаний и организаций отметили, что сегодня они сталкиваются с большим количеством кризисов, чем 10 лет назад. За последние два года $80 \%$ организаций во всем мире были вынуждены мобилизовать свои команды по непрерывности бизнеса и кризис-менеджменту. При этом возглавляют список кризисов, требующих вмешательства руководства, инциденты с кибербезопасностью и промышленные аварии.

В будущее японский бизнес смотрит без оптимизма: большая часть респондентов уверена, что в ближайшие 5 лет число кризисов только увеличится. Такой ответ дали: в сфере энергетики и природных ресурсов - 78\% опрошенных; в сфере технологий, медиа и телекоммуникаций - 70\% респондентов; в сфере потребительских 


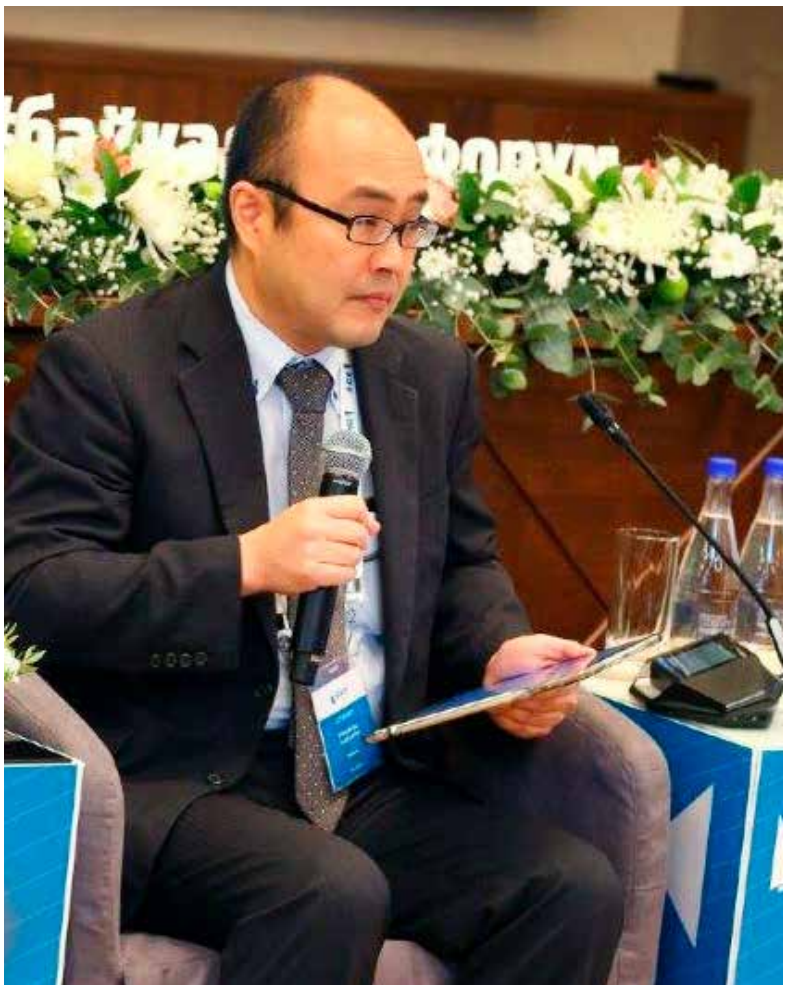

Масахико Сугияма (Masahiko Sugiyama), руководитель практики по антикризисному управлению, японский партнер Deloitte

и промышленных товаров - 67\%; в сфере медицины и здравоохранения - 58\%, а в сфере финансовых услуг - и вовсе $87 \%$.

С какими же трудностями сталкиваются компании? Изменения в государственной политике и нормах регулирования, системные сбои, корпоративные скандалы, промышленные аварии и киберинциденты стоят на первом месте в списке кризисов, которые оказывают наибольшее влияние на японские организации. Причем именно эти риски стали той областью, где наибольшее количество респондентов не были уверены в своей способности справиться с этими проблемами.

Однако несмотря на ожидание кризисных явлений, большинство компаний не готовы встретить кризис. Даже наличие планов непрерывности бизнеса и кризис-менеджмента не означает, что они готовы справиться с ними. И в этом зазоре между осведомленностью и готовностью кроется главная уязвимость.

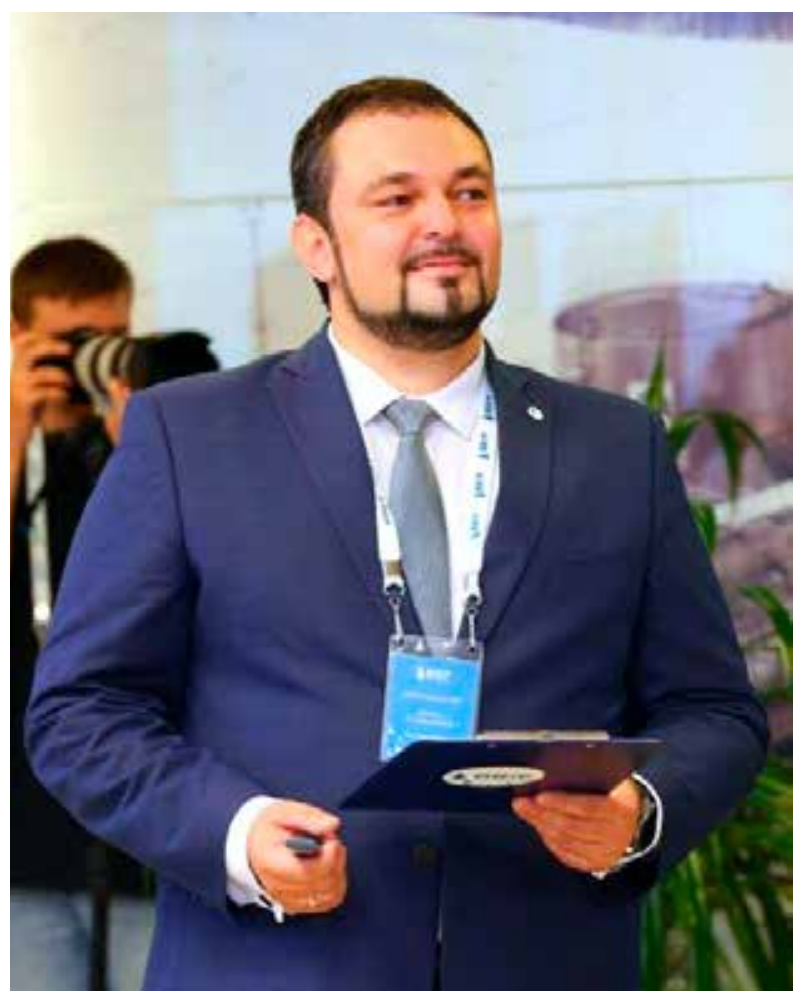

Денис Скороходов, начальник отдела управления рисками Иркутской нефтяной компании

Эффективным решением может стать активное участие внешних специалистов. Внешняя поддержка помогает ускорить эффективное реагирование и восстановление. Вообще, при эффективном антикризисном управлении кризисы могут быть полезны и даже делают компанию сильнее, производительнее и устойчивее. О том, какие инструменты риск-менеджмента для этого могут быть использованы, был представлен практический кейс.

Результаты практических исследований в области непрерывности бизнеса представил Юрий Веселов, PWC, менеджер отдела анализа и контроля рисков. Он рассказал о драйверах внедрения непрерывности бизнеса, распределении моделей управления непрерывностью бизнеса, вызовах и барьерах на пути построения эффективной системы и представил практический кейс «Кризисное реагирование как элемент устойчивости бизнеса» - со сценарием учений, полезными рабочими материалами, наблюдениями и решениями. 
«Мы хотим, чтобы в конечном итоге было меньше экстренных ситуаций», - заявил представитель Министерства энергетики РФ Василий Чубоксаров, директор Центра компетенций технологического развития ТЭК. По его мнению, регламенты должны составляться с учетом мнения индустрии, и чтобы услышать мнение компаний, лучше понять запросы бизнеса, для этого он и приехал на форум. Но не с пустыми руками, а с докладом на тему «Определение и оценка рисков, связанных с импортом технологий в ТЭК».

О том, как построен план непрерывности деятельности компании Норникель, подробно рассказал руководитель по направлению Службы риск-менеджмента Евгений Теленков. Собственно говоря, планов три: так называемый красный план - для опасных производственных объектов. В нем расписаны основные действия плюс комму- никации с внешним миром и заинтересованными сторонами внутри компании. Реализация красного плана стартует в первые же секунды после аварии, чтобы спасти людей и имущество. Желтый план вступает в силу на следующий день. Это план поддержания деятельности. Он направлен на то, чтобы не дать полностью остановиться производственному процессу. Зеленый план - план восстановления. Зачастую он предполагает проектирование, капитальное строительство и растягивается на годы. Тем не менее этот план позволяет компании чувствовать себя увереннее, заранее определив порядок возможных работ, ответственные стороны и сроки восстановления.

В Газпромнефти, по признанию Дмитрия Гончарова, руководителя направления Непрерывности деятельности и рисков ПАО «Газпром нефть», план непрерывной деятельности состоит из двух

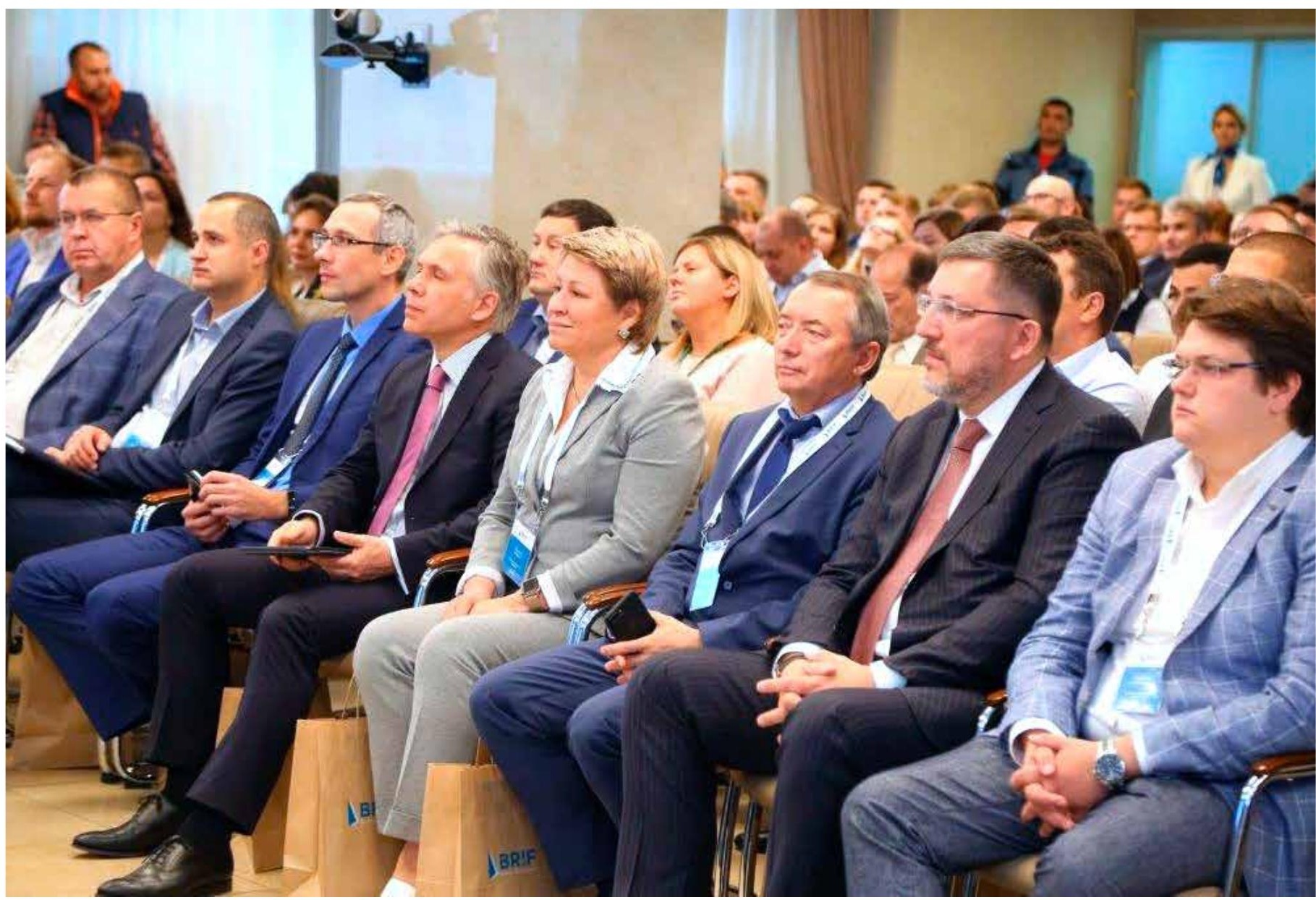




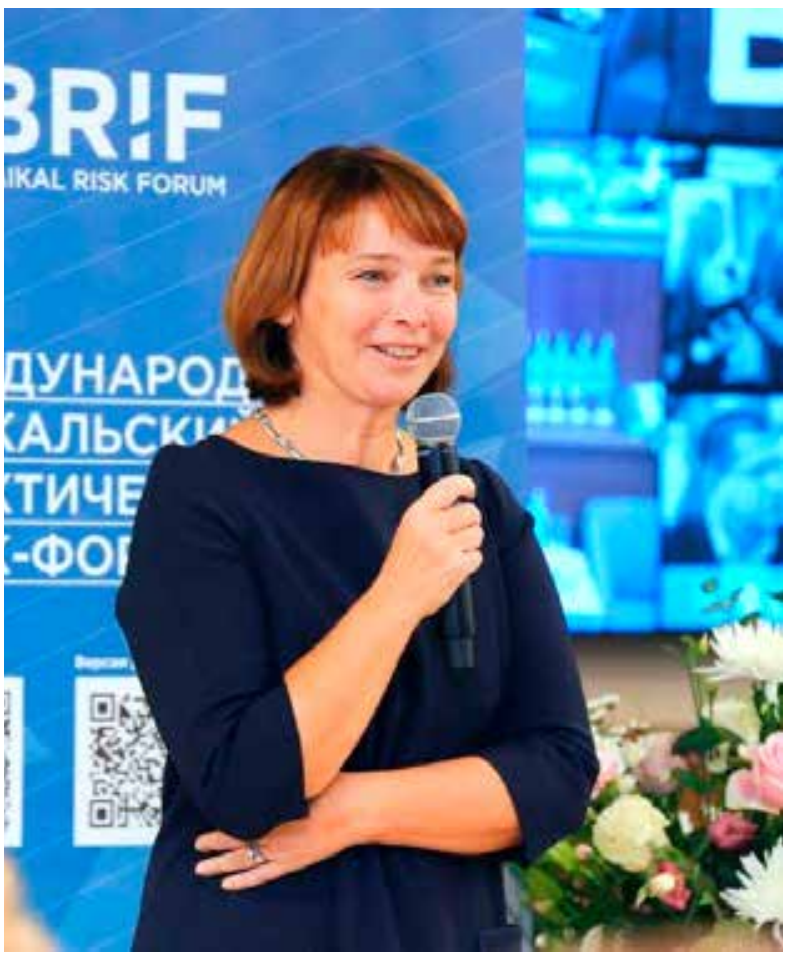

Ольга Высоцкая, член Совета директоров, независимый директор Иркутской нефтяной компании

частей. Первая - это объемный документ, который детально описывает все, что надо знать, включая телефоны и регламенты. А вторая часть представляет собой короткую схему действий с карточками участников, указывающими, кто и что должен делать. Такой план должны писать все лица, которые в него вовлечены. План постоянно совершенствуется - для этого в компании проводятся учения.

Важные проблемы, с которыми неизбежно сталкиваются компании, обозначили спикеры Иркутской нефтяной компании. Это угрозы экологического характера и риски, которым подвержены сотрудники опасных производств. Будучи экспертами в этой сфере, рисковики Иркутской нефтяной компании, Газпрома и ERG делились опытом работы в условиях подверженности рискам чрезвычайных ситуаций, в том числе работы в условиях задымленности (пожары в лесах Сибири).
Управление трудовыми ресурсами на форуме рассматривалось не только с точки зрения гарантирования максимально возможной безопасности труда, но и с точки зрения управления кадровым резервом как системы обеспечения непрерывности бизнеса.

Много внимания на форуме было уделено тренду последнего времени - киберрискам. По мнению Сергея Саламатова, руководителя дирекции управления рисками Интер РАО, «у цифровизации есть темная сторона». Ее можно увидеть на примере Венесуэлы, где кибератаки лишили практически всю страну электроэнергии. От кибератак напрямую зависит непрерывность бизнеса, поэтому так важно задумываться о защите от внешних киберугроз. Но не стоит забывать и об авариях, ведь по данным Ростехнадзора причиной остановки производств в 71\% случаев является человеческий фактор. А значит, надо развивать компетенции на местах, убежден Саламатов.

Представитель Microsoft Вячеслав Беляков поделился способами, которыми компания борется с киберугрозами и пытается их предотвратить. Артем Артемов, ведущий специалист по компьютерной криминалистике GROUP-IB, осветил киберриски при электронном документообороте, а Анастасия Селезнева, руководитель управления АльфаСтрахования, представила страхование от киберрисков как способ защиты от современных ИТ-угроз.

В целом за два дня работы форума было сделано немало интересных докладов, прозвучало немало ярких выступлений. Нам приятно было увидеть в роли спикера автора нашего журнала Артема Салтанова, представившего доклад на тему «Выход из строя крупного технологического производственного оборудования - опыт, разбор, вывод».

Работа в формате круглых столов и мастерклассов шла напряженная и плодотворная. Рискакадемия и ISAR провели мастер-класс по использованию инструментов количественной оценки для киберрисков, а компания Deloitte организовала бизнес-игру по управлению непрерывностью бизнеса. Наш журнал «Проблемы анализа риска» разыграл в форме лотереи пять подписок на электронную версию издания на 2020 год. 


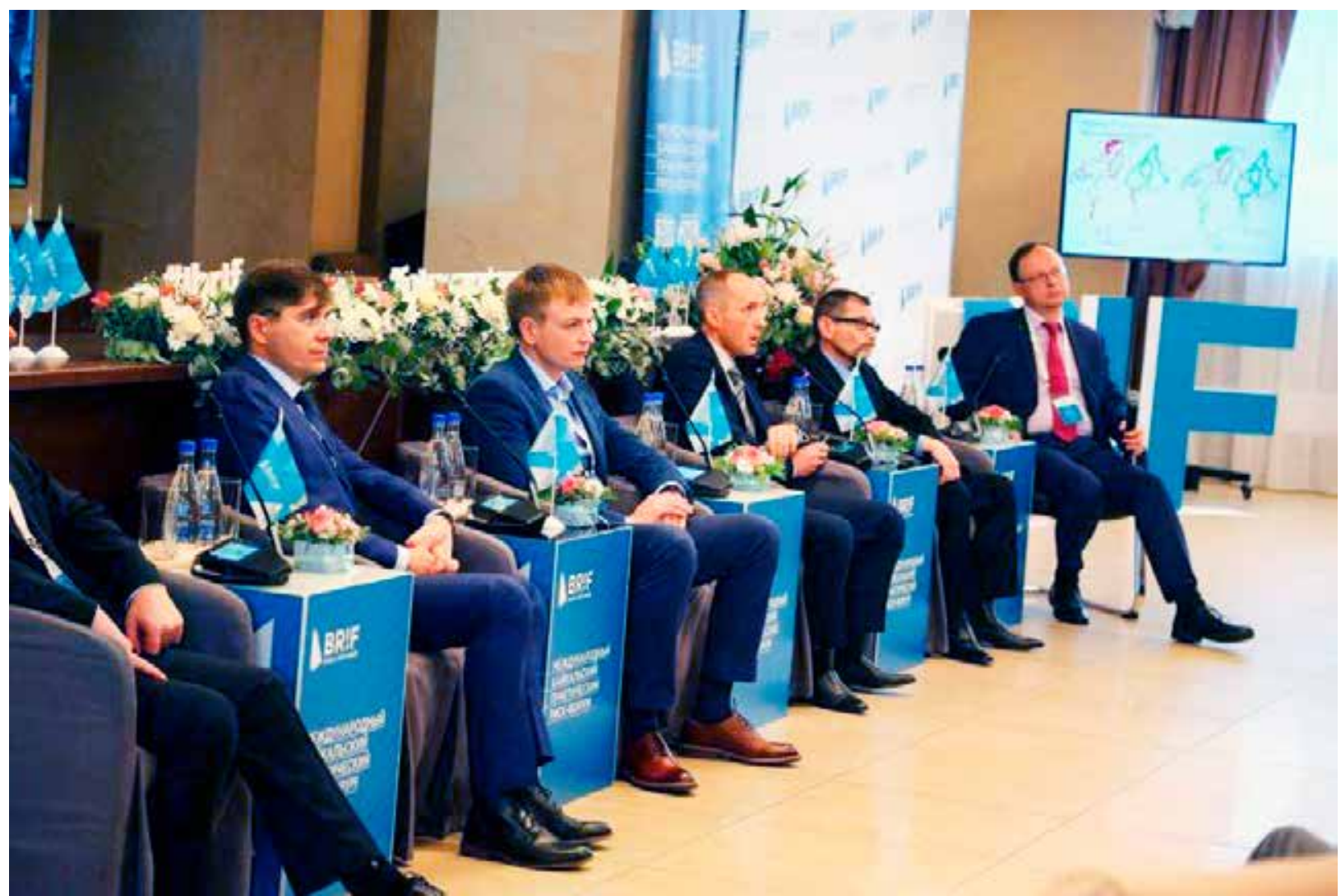

Благодаря специальному мобильному приложению деловое общение шло в режиме нон-стоп. В ходе выступлений через приложение слушатели задавали вопросы спикерам, назначали деловые встречи коллегам, обменивались мнениями. На протяжении всего форума велась онлайнтрансляция, а используемая техника скрайбинга помогала фиксировать важные моменты выступлений.
Расставаясь, участники форума от души пожелали Байкальскому риск-форуму главного - непрерывности. Третий форум завершен - да здравствует четвертый!

Элина Севернюк, редакиия журнала «Проблемы анализа риска» 